\title{
Mathematical Model of Three Dimensional Spouted Bed Using Distinct Element Method
}

\author{
S. Laorratanasak ${ }^{1}$, Thongchai Srinophakun ${ }^{2, *}$ and Parichat Mongkolsaowanit ${ }^{3}$ \\ ${ }^{1}$ Chemical Engineering Practice School, King Mongkut's University of Technology Thonburi \\ Bangkok, Thailand \\ ${ }^{2}$ Department of Chemical Engineering, Kasetsart University \\ Bangkok, Thailand \\ ${ }^{3}$ Department of Electrical Mechanical Manufacturing Engineering, Kasetsart University \\ Bangkok, Thailand \\ *Corresponding author's email: fengtcs [AT] hotmail.com
}

\begin{abstract}
Spouted bed was simulated by a combining of Discrete Element Method (DEM) and Computational Fluid Dynamics (CFD) technique. In the simulation, DEM based on the Newton's second law of motion was used to solve the particle motion and the fluid motion were obtained by CFD with the SIMPLE method and Upwind scheme. Programming was developed in Standard-C language and MATLABTM was used to visualize the results. The size of particles focused on this simulation is $2.5 \mathrm{~mm}$ in diameter (the density $=2,500 \mathrm{~kg} / \mathrm{m3}$, stiffness $=800 \mathrm{~N} \mathrm{~m}-1$ ). The time step used to maintain the stability of the simulation was 6.5 10-5 sec.
\end{abstract}

In this simulation, three level of the static bed height were studied: 45, 58, and $70 \mathrm{~mm}$. The operating parameter effects (the static bed height on the pressure drop across the bed and the minimum spouting velocity) were investigated. The pressure drop across the bed and the minimum spouting velocity increased corresponding to the level increment. In the study of the pulsed and multi-pulsed frequency, it was found that the higher number of frequency introduced the higher heat transfer to the particles. Moreover, the effect of each type of flow on the average particles temperature was studied. The continuous flow gave the highest average particles temperature. Even though, the single pulsed flow and the multiple pulsed flows gave the lower heat transfer than continuous flow, the multiple flows produced a very good distribution in the heat transfer and also can reduce the dead zone problem of the spouted bed.

Keywords - Spouted Bed / Distinct Element Method (DEM) / Computational Fluid Dynamic (CFD) / Heat Transfer

\section{INTRODUCTION}

Spouted bed is the one of the technique which allows the direct contact between the fluid and solid particle that can be applied to the many industries. This technique is suitable for the large size and high density particle that the fluidization technique cannot apply. However, due to several limitations of the conventional spouted bed such as, low annulus aeration, and low capacity per unit floor space, many modified spouted bed have been proposed.

The purpose of this research is to develop a discrete particle simulation by adopting distinct element method for momentum transfer in the spouted bed. The simulation can give the detailed data much more than from the experiment without disturbing the system. Moreover, varying the operating parameters to obtain the optimum condition is easier. The Distinct Element Method (DEM) established by Cundall and Strack[1], referred to as discrete particle method, in which the motion of individual particle is obtained by solving Newton's second law of motion, has emerged to be an important tool in particle technology research. For Computational Fluid Dynamics (CFD), it is the analysis of system involving fluid flow, heat transfer, and associated phenomena by mean of computer-based simulation. The flow field of any fluid can be expressed by these principles in terms of mathematical equations. The equations usually are partial differential equations which cannot be solved analytically. Therefore, a discretization method is applied to approximate the differential equations. However, the disadvantage is the long computational time. Therefore, an appropriate time step in the calculation should be chosen. 


\section{THEORY}

\subsection{Spouted Bed}

The spouted bed was invented in the early 1950s [2] for drying of grain. Spouted bed has recently been considered for the gasification and combustion of coarse coal, biomass and waste products.

This technique was described as "a variant of fluidization which permits agitation of solid materials that are too coarse and uniform in size for good fluidization."[2] The hydrodynamic features of a spouted bed are different from those of a fluidize bed in that a systematic cyclic movement is imparted to the solids which travel upward through a dilute axial zone and upwards through a small orifice at the centre of conical base rather than distributing it evenly across the bed. This achieved by forcing the fluid upwards through a small orifice at the centre of conical base.

\subsection{Particle Motion}

To simulate the spouted bed, particles motions can be calculated from total forces acting on particles. The inter particle forces can be determined by using DEM. The entire volume of the bed is divided into cubical boxes and every sphere and wall is then mapped into the boxes.

A particle in a spouted bed can have two types of motion: translational and rotational. From the Newton's second law, the equations for individual particles, (1) and for translational and rotational can be written as:

$$
\begin{gathered}
\mathrm{m} \frac{\mathrm{dv}}{\mathrm{dt}}=\mathrm{f}_{\mathrm{c}}+\mathrm{f}_{\mathrm{d}}+\mathrm{f}_{\mathrm{f}}+\mathrm{mg} \\
\mathrm{I} \frac{\mathrm{d} \omega}{\mathrm{dt}}=\mathrm{T}
\end{gathered}
$$

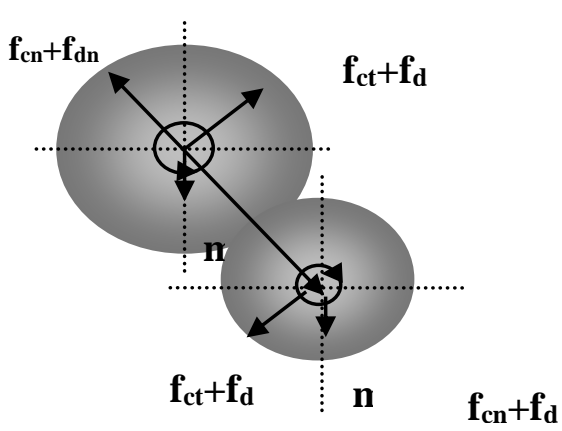

Figure 1. Schematic of the 3D axes and spheres A and B in collision

The Cundall's distinct element method was used in this work to calculate the contact forces between two spheres. The mechanics of sphere-sphere collisions are outlined in Fig.1. Collision between spheres and walls are modeled in a similar manner. In the following, a model formulation leading up to the calculation of forces acting on sphere A due to a collision with sphere B is shown.

The unit normal vector, , from the center of sphere A to that of sphere B is

$$
\mathrm{n}_{\mathrm{i}}=\left(\mathrm{u}_{\mathrm{B}, \mathrm{i}}-\mathrm{u}_{\mathrm{A}, \mathrm{i}}\right) / \mathrm{d}
$$

where $\mathrm{d}$, the distance between the centers, is given by

$$
\mathrm{d}=\left(\sum_{\mathrm{i}}\left(\mathrm{u}_{\mathrm{B}, \mathrm{i}}-\mathrm{u}_{\mathrm{A}, \mathrm{i}}\right)\left(\mathrm{u}_{\mathrm{B}, \mathrm{i}}-\mathrm{u}_{\mathrm{A}, \mathrm{i}}\right)\right)^{1 / 2}
$$


The velocity of $\mathrm{B}$ with respect to $\mathrm{A}$, represented as $v_{\mathrm{i}}$ is,

$$
\mathrm{v}_{\mathrm{i}}=\mathrm{v}_{\mathrm{B}, \mathrm{i}}-\mathrm{v}_{\mathrm{A}, \mathrm{i}}
$$

The vectors that represent the normal, $v_{n, i}$, and tangential, $v_{t, i}$, components of $v_{\mathrm{i}}$ are

$$
\begin{aligned}
& v_{n, i}=v_{j} n_{j} n_{i} \\
& v_{t, i}=v_{i}-v_{n, i}
\end{aligned}
$$

The vector $\omega_{\mathrm{i}}$ which represents the angular velocity of the center of B with respect to that of A is normal to both $v_{n, i}$ and $v_{\mathrm{t}, \mathrm{i}}$. It is the angular velocity of the contact normal from the center of $\mathrm{A}$ to that of $\mathrm{B}$. The magnitude of $\omega_{\mathrm{i}}$ is equal to

$$
\mathrm{V}_{\mathrm{t}}=\left(\mathrm{V}_{\mathrm{t}} \mathrm{V}_{\mathrm{t}}\right)^{1 / 2}
$$

divided by the distance $\mathrm{d}$. Thus wi may be represented as follows

$$
\omega_{\mathrm{r}, \mathrm{i}}=\varepsilon_{\mathrm{ijk}} \mathrm{n}_{\mathrm{j}} v_{\mathrm{t}, \mathrm{k}} / \mathrm{d}
$$

where, $\varepsilon_{\mathrm{ijk}}$ is the alternating tensor of third rank.

The shear velocity, $v_{\mathrm{s}, \mathrm{i}}$, across the contact is a vector that is composed of the tangential velocity, $v_{\mathrm{t}, \mathrm{i}}$, and a component due to the rotations of the two spheres. The shear velocity is

$$
v_{\mathrm{s}, \mathrm{i}}=v_{\mathrm{t}, \mathrm{i}}+\varepsilon_{\mathrm{ijk}} \mathrm{n}_{\mathrm{j}}\left(\omega_{\mathrm{A}, \mathrm{k}} \mathrm{r}_{\mathrm{A}}+\omega_{\mathrm{B}, \mathrm{k}} \mathrm{r}_{\mathrm{B}}\right)
$$

The normal force $\mathrm{f}_{\mathrm{cn}, \mathrm{i}}$ is in the direction of the normal vector, and has a magnitude $\mathrm{f}_{\mathrm{cn}}$

The magnitude of the normal force is updated at every time step. With k representing the normal stiffness, the $\mathrm{n}$ normal force at the contact is updated as

$$
\mathrm{f}_{\mathrm{cn}}=\mathrm{f}_{\mathrm{cn}}^{\prime}-\mathrm{v}_{\mathrm{n}} \mathrm{k}_{\mathrm{n}} \Delta \mathrm{t}
$$

where $\mathrm{f}_{\mathrm{cn}}^{\prime}$ is the normal force at the end of the previous time step, and $v_{\mathrm{n}}=\left(v_{\mathrm{n}, \mathrm{i}} \mathrm{v}_{\mathrm{n}, \mathrm{i}}\right)^{1 / 2}$

Both magnitude and direction of shear force, $\mathrm{f}_{\mathrm{cs}, \mathrm{i}}$, must be updated at each time step. If $\mathrm{f}_{\mathrm{cs}, \mathrm{i}}^{\prime}$ represents the shear force at the end of the previous time step, the shear force $f_{c s, i}$ at the end of the current time step, with $k_{s}$ representing the shear stiffness at the contact is given by

$$
\mathrm{f}_{\mathrm{cs}, \mathrm{i}}=\mathrm{f}_{\mathrm{cs}, \mathrm{j}}^{\prime}-\mathrm{k}_{\mathrm{s}} \mathrm{v}_{\mathrm{s}, \mathrm{i}} \Delta \mathrm{t}
$$

First, the magnitude of the shear force is calculated to see if its value is greater than the maximum that is permitted. The maximum permissible shear force, $\mathrm{f}_{\mathrm{s}, \max }=\mu \mathrm{f}_{\mathrm{cn}}$, where $\mu$ is the coefficient of friction at the contact. If this is the case, it is assumed that slip occurs and the magnitude of the shear force is scaled down to $\mu \mathrm{f}_{\mathrm{cn}}$. The calculation cycle is continued with this new value of the shear force. Otherwise, the calculated value is taken.

Since the system tends to be stationary due to the inelastic collisions between particles if no external energy is added to it, the viscous contact damping force is introduced to consume the system energy during particle collisions.

$$
\mathrm{f}_{\mathrm{dn}, \mathrm{i}}=-\eta_{\mathrm{n}} v_{\mathrm{n}} \mathrm{n}_{\mathrm{i}}
$$




$$
\mathrm{f}_{\mathrm{ds}, \mathrm{i}}=-\eta_{\mathrm{s}} \mathrm{v}_{\mathrm{s}, \mathrm{i}}
$$

$f_{d n i}$ and $f_{d s, i}$ stand for the components of the normal and the shear contact damping forces where $\eta_{\mathrm{n}}$ and $\eta_{\mathrm{s}}$ stand for normal and shear contact damping coefficients.

In modeling inter-particle force, three parameters, namely the spring constant, the coefficient of friction, and viscous contact damping coefficient, must be available. Only the friction coefficient, $\gamma$, is measurable and can be described an empirical value. Therefore, the stiffness or spring constant, $\mathrm{k}$, must be determined first. The stiffness can be calculated using the Hertzian contact theory when physical properties such as the Young's modulus and Poisson ratio are known. For the case of two spheres of the same radius $\mathrm{R}, \mathrm{k}$ is expressed by;

$$
k=\frac{\sqrt{2 R} E_{p}}{3\left(1-\sigma_{p}{ }^{2}\right)}
$$

And $\mathrm{k}$ for contact between a sphere and wall is given by

$$
\mathrm{k}=\frac{4 \sqrt{\mathrm{R}}}{3} / \frac{1-\sigma_{\mathrm{p}}^{2}}{\mathrm{E}_{\mathrm{p}}} \cdot \frac{1-\sigma_{\mathrm{w}}^{2}}{\mathrm{E}_{\mathrm{w}}}
$$

Fluid drag force is another force between particle and fluid. This force depends on the relative velocity of fluid and particle, and the presence of other surrounding particles. This force represents the interaction between the fluid and the particles, and is given by

$$
\mathrm{f}_{\mathrm{f}, \mathrm{i}}=\frac{\beta}{\rho_{\mathrm{g}}}\left(\bar{v}_{\mathrm{p}, \mathrm{i}}-\mathrm{u}_{\mathrm{i}}\right)
$$

Where $\bar{v}_{p, i}$ is the averaged of the particle velocities. The coefficient $\beta$ is given by Ergun's equation for the dense region and the equation derived by $\mathrm{Wen}$ and $\mathrm{Yu}$ for the dilute region;

\subsection{Fluid Motion}

The other motion that is also very significant in simulation of spouted bed is fluid motion. For fluid motion, it is reasonable to make a calculation based on locally averaged quantities. As is usual in many numerical simulation calculations of flow fields, the finite volume method was used in the present simulation. The flow domain was divided into cells, the size of these cells are larger than the particle size. All quantities such as velocity and pressure are averaged in the cell. When the set of algebraic equations are obtained, TDMA (Tri-Diagonal Matrix Algorithm) is used to solve these equations. SIMPLE (Semi-Implicit Method for Pressure-Linked Equations) is the algorithm used to calculate pressure.

Equation of continuity;

$$
\frac{\partial \varepsilon}{\partial t}+\nabla \cdot(\varepsilon \mathbf{u})=0
$$

Equation of motion; 


$$
\begin{gathered}
\frac{\partial\left(\rho_{\mathrm{f}} \varepsilon \mathrm{u}\right)}{\partial \mathrm{t}}+\nabla \cdot\left(\rho_{\mathrm{f}} \varepsilon \mathrm{uu}\right)=-\varepsilon \nabla \mathrm{p}-\mathrm{F} \\
\mathrm{F}=\frac{\sum_{\mathrm{i}=1}^{\mathrm{n}} \mathrm{f}_{\mathrm{f}, \mathrm{i}}}{\Delta \mathrm{V}}
\end{gathered}
$$

\section{PROGRAMMING}

\subsection{Assumption}

1.Particles are concerned as Geldart group D to neglect the effect of agglomerate.

2.Particles are Nonhygroscopic capillary- porous media in spherical shape.

3. The calculation is based on a three- dimensional model.

4. The particle-to-particle adhesion forces and buoyancy force can be neglected

5. Particles have a soft sphere interaction (a Hookean linear spring, a dash pot and a friction slider with Coulomb's friction law.)

6. Gas is inviscid except when considering the fluid drag on particle.

7. The temperature of particles is uniform.

8. Physical properties such as, thermal conductivity and viscosity of the gas and heat capacity of the particle are constant.

9. Particle-to-gas heat transfer coefficientis calculated by Ranz-Marshall correlation.

10 Particle-to-particle heat transfer is neglected because of short contact time.

11.Heat loss through the bed wall is neglected.

12.The radiation heat transfer is unimportant.

The simulation parameters of particle and fluid are summarized in Table 1 . The configuration of spouted bed chamber for both rectangular shape and cylindrical shape used in this are shown in Table 2.

Table 1. Parameters for the Simulation

\begin{tabular}{|l|l|}
\hline \multicolumn{1}{|c|}{ Particle } & \multicolumn{1}{c|}{ Gas Phase } \\
\hline Diameter $\quad 2.5 \mathrm{~mm}$ & Density $1.205 \mathrm{~kg} \mathrm{~m}^{-3}$ \\
Density $\quad 2,500 \mathrm{~kg} \mathrm{~m}^{-3}$ & Viscosity $1.81 \times 0^{-5} \mathrm{~N} \mathrm{~m}^{-2} \mathrm{~s}^{-1}$ \\
Stiffness $\quad 800 \mathrm{~N} \mathrm{~m}^{-1}$ & \\
Coefficient of friction 0.3 & \\
Coefficient of restitution 0.9 & \\
\hline
\end{tabular}

Table 2. The Configuration of Spouted Bed Chamber

\begin{tabular}{|l|l|}
\hline \multicolumn{1}{|c|}{ Rectangular Bed } & \multicolumn{1}{c|}{ Cylindrical Bed } \\
\hline Chamber cross-section $30 \times 30 \mathrm{~mm}$ & Chamber diameter $30 \mathrm{~mm}$ \\
\hline Chamber height $200 \mathrm{~mm}$ & Chamber height $200 \mathrm{~mm}$ \\
\hline $\begin{array}{l}\text { Orifice length } 6 \mathrm{~mm} \\
\text { Orifice width } 6 \mathrm{~mm}\end{array}$ & Orifice diameter $6 \mathrm{~mm}$ \\
\hline
\end{tabular}


The calculation flow diagram used in programming is shown in Figure 2.

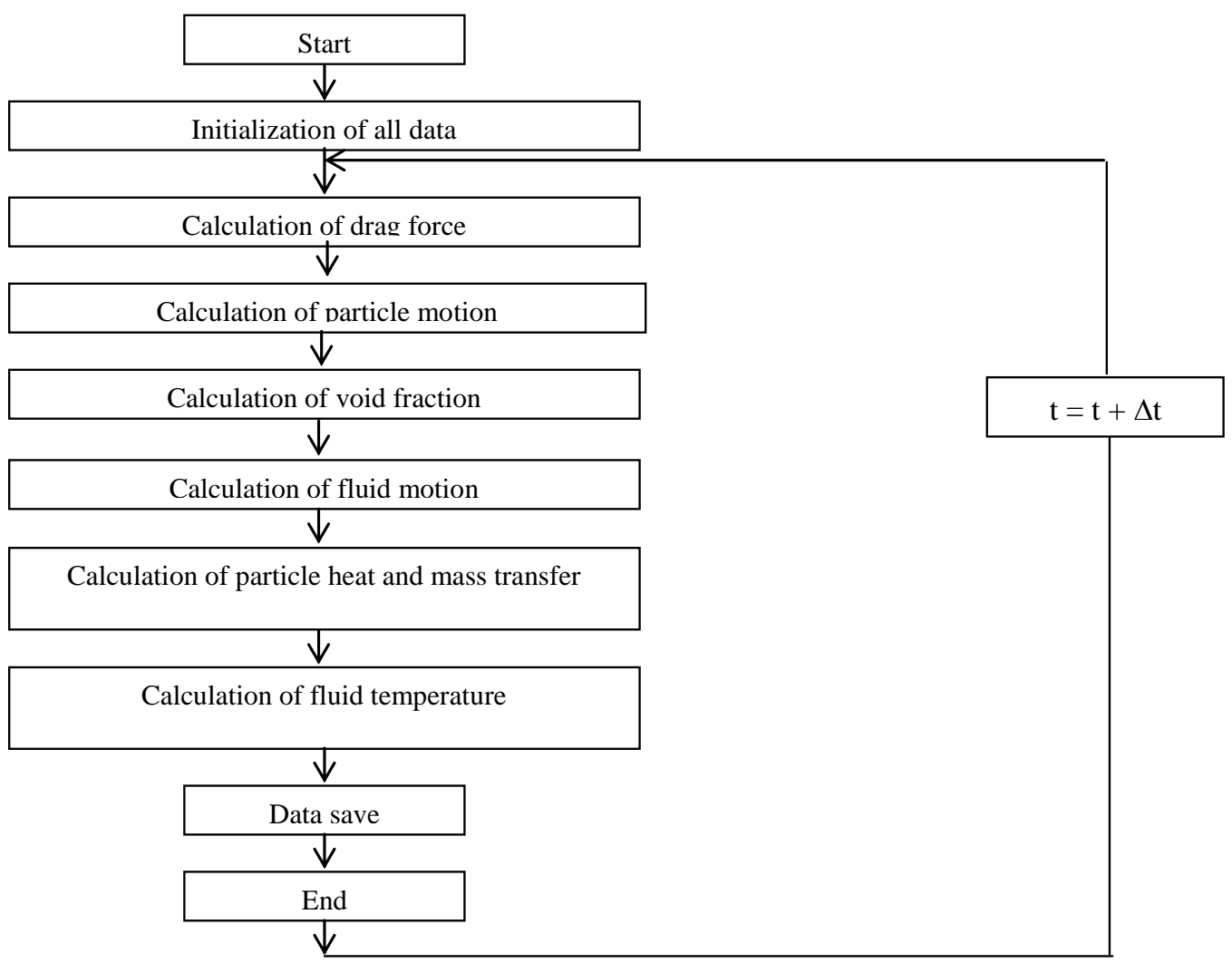

(a)

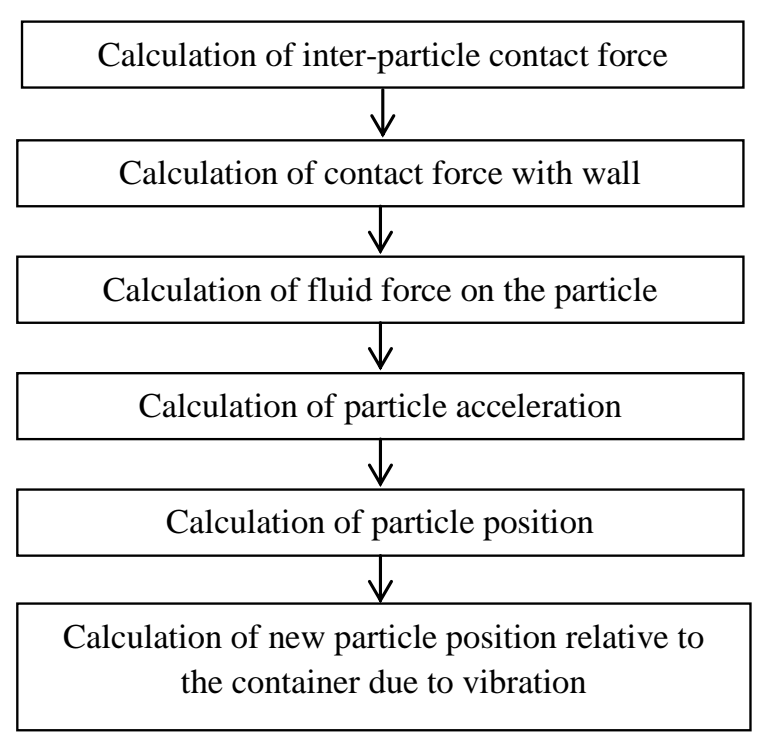

(b)

Figure 2. Calculation Flow Chart: (a) Main

Flow; (b) Particle Motion 


\section{RESULT AND DISCUSSION}

\subsection{Effect of static bed height on the pressure drop}

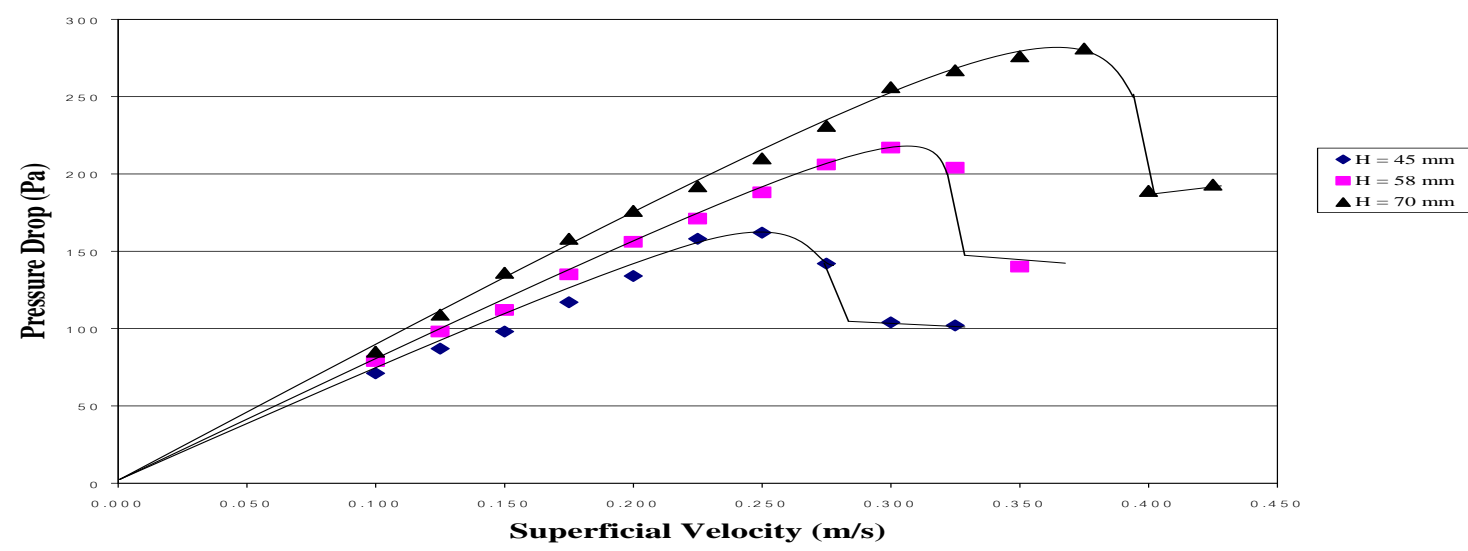

Figure 3. Pressure Drop Versus Superficial Gas Velocity for different bed height

In general, the pressure drop increases with the increasing of the flow rate. The pressure drop will increase until it reaches the maximum value. Beyond this point, the height of the hollow internal spout becomes large in comparison with the packed solids above the spout. Therefore the pressure drop will decrease. The pressure will decrease until the certain point which enough solids have been displaced from the central core to cause an expansion of the bed. From the result in Figure 3, the trends of the pressure drop for each case agree with the step explained above. For the effect of the static bed height, the pressure drop across the bed will increase with the increment of bed level because a higher number of particles increased and it will cause to the higher in resistance for the air to make the spout.

\subsection{Effect of static bed height on the minimum spouting velocity}

The minimum spouting velocity depends on solid, fluid properties and the geometry of the bed. The value of the minimum spouting velocity can be obtained by increasing the superficial gas velocity inlet until the spouting occurs in the bed. Then, the superficial gas velocity is reduced slowly until the spouting disappears. In the simulation, the superficial gas velocity was changed along with the time and it showed that the step function should be applied since there are the lag time between the change in velocity and the respond to the bed. And the results from varying the static bed height on the minimum spouting velocity are shown in below.

Table 3. The effect of the static bed height on the minimum spouting velocity

\begin{tabular}{|c|c|c|}
\hline $\begin{array}{c}\text { Bed height } \\
(\mathrm{mm})\end{array}$ & Number of Particles & Minimum Spouting Velocity (m/s) \\
\hline 45 & 3000 & 0.26 \\
\hline 58 & 3750 & 0.30 \\
\hline 70 & 4500 & 0.38 \\
\hline
\end{tabular}

The results demonstrate that the minimum spouting velocity increases with the increasing of bed height. This value goes up because the higher number of particles. 


\subsection{Effect of frequency of pulsed flow spouting}

The 6,000 particles used in this system are increased because the increasing of the cross sectional area for this study. The frequencies are varied from 2.0, 2.5, and 3.33 hertz and the amplitude is 0.4 . The particle motion in spouted bed at each frequency is shown in Figures 4-6.
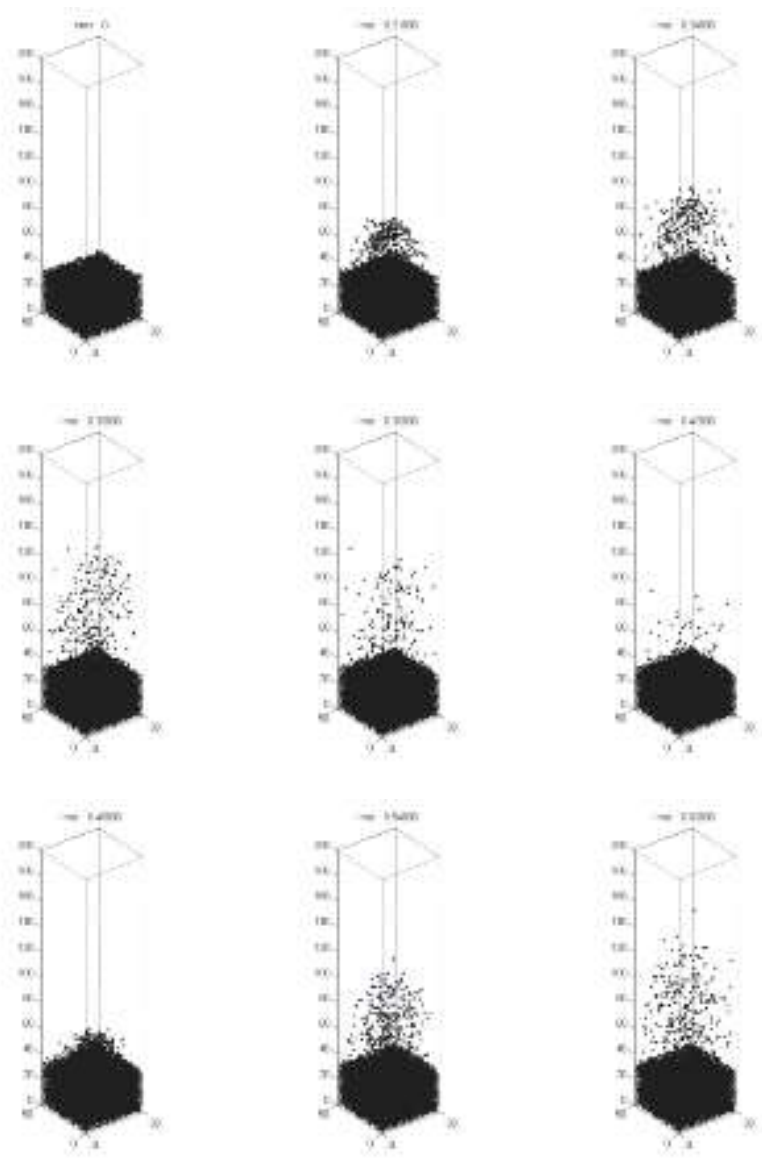

Figure 4. The particles motion in spouted bed at frequency $=3.33 \mathrm{~Hz}$
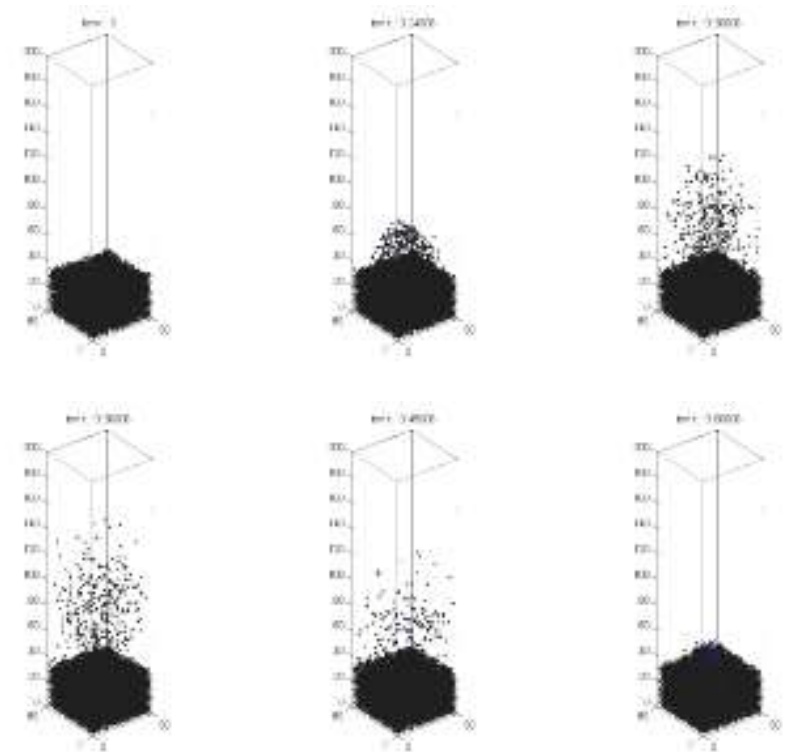

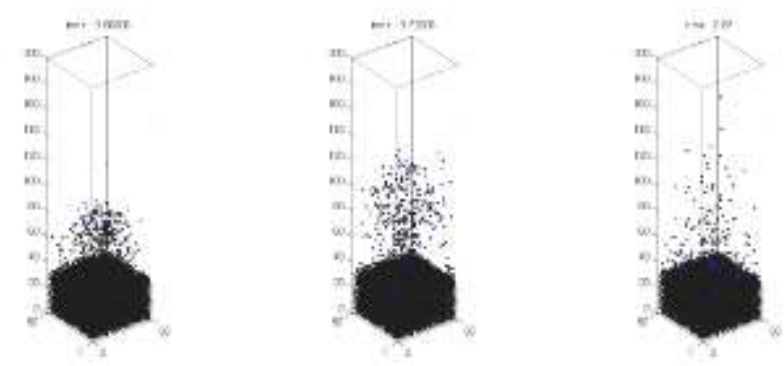

Figure 5. The particles motion in spouted bed at frequency $=2.5 \mathrm{~Hz}$
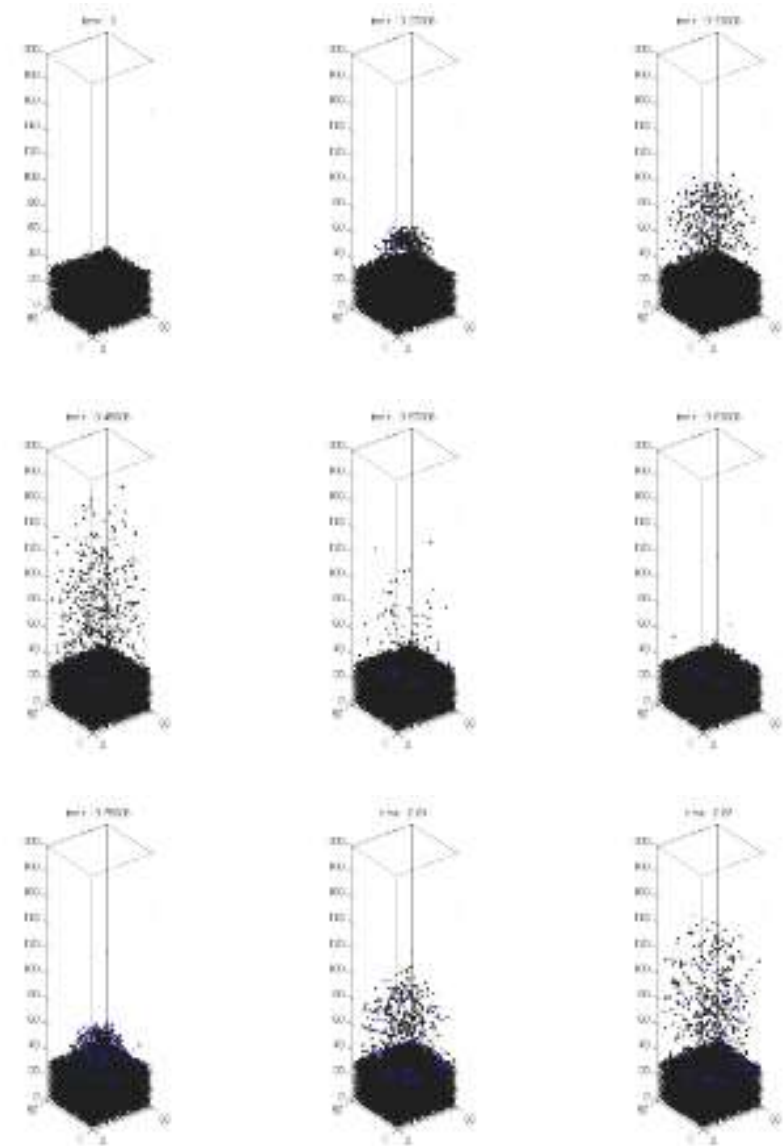

Figure 6. The particles motion in spouted bed at frequency $=2.0 \mathrm{~Hz}$

The profiles of the particles motion from these figures are very similar however the temperatures of these particles are different. The plots of average particle temperature versus time are demonstrated in figure 7 below.

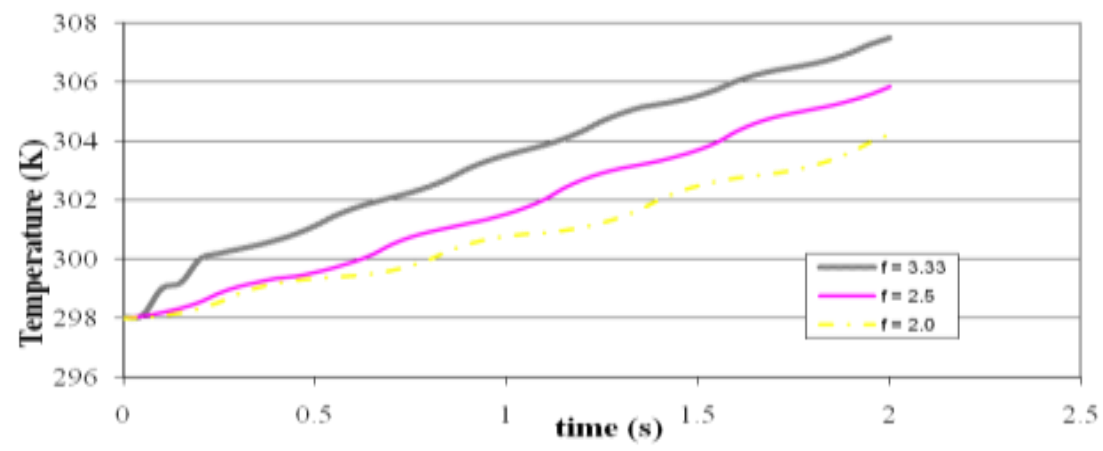

Figure 7. Effect of pulsed frequency on average particle temperature 
The average particle temperature increased along with time. When the frequency was changed, it will effect to the average particle temperature. The higher frequency of pulsed flow of hot air gives the higher heat transfer rate to the particles. Therefore, the average particle temperature will increase if the frequency is increased as shown in figure 7.

\subsection{Effect of frequency of multiple pulsed flow spouting}

The number of orifices at the bottom plate is changed from the 1 hole in the center to the 4 holes. Hot air is fed through the orifice one by one orifice from orifice 1 to orifice 2, 3, and 4 then goes back to orifice 1 again in the cycle. The 6,000 particles were used in this system. The plots of the superficial gas velocity used in the model for various frequency of pulsing and the motion of particles in the multiple pulsed spouted bed at frequency $=3.33,2.5$, and 2.0 hertz are shown in Figures 8-10.
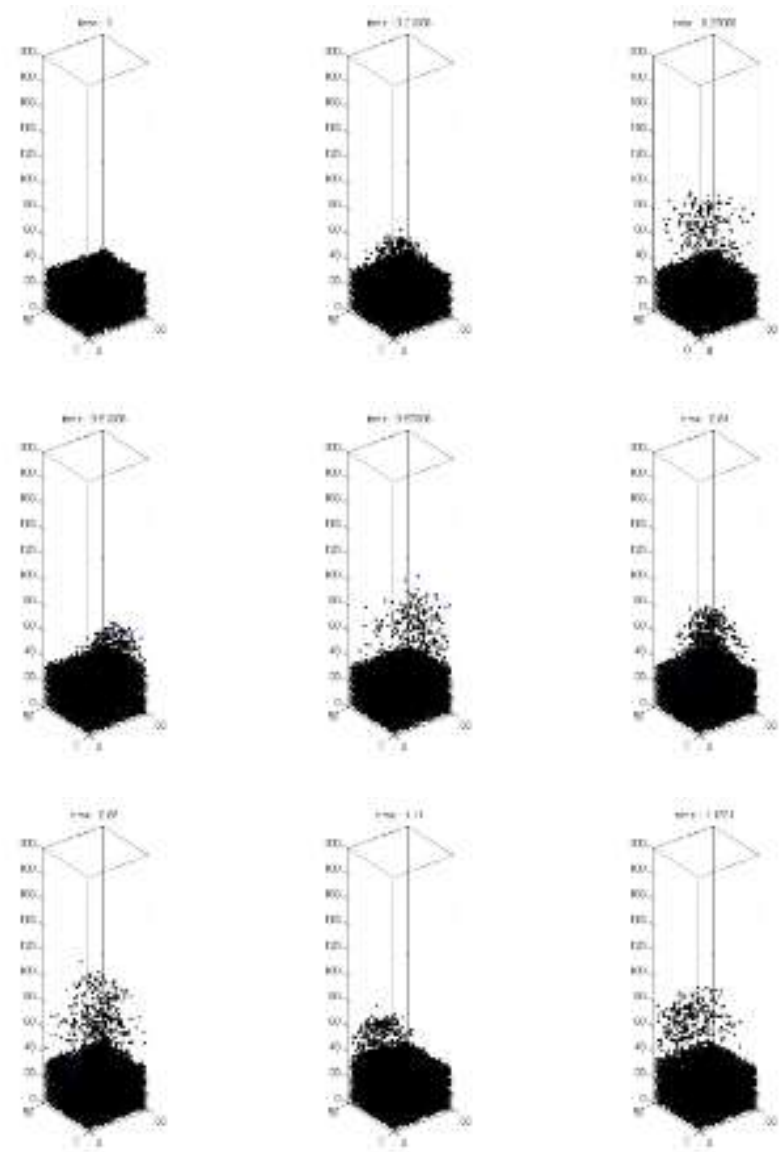

Figure 8. The motion of particle in multi-pulsed spouted bed at frequency $=3.3 \mathrm{~Hz}$
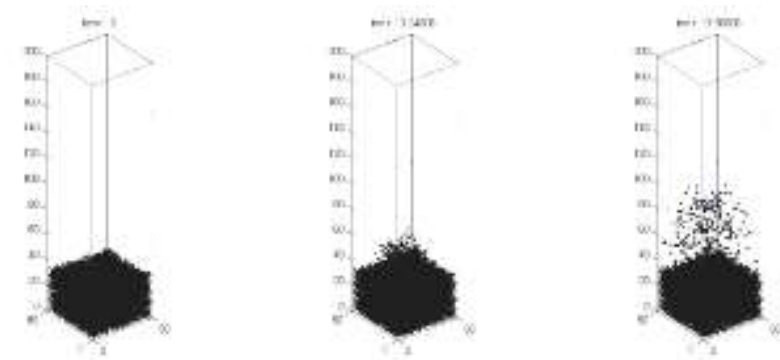

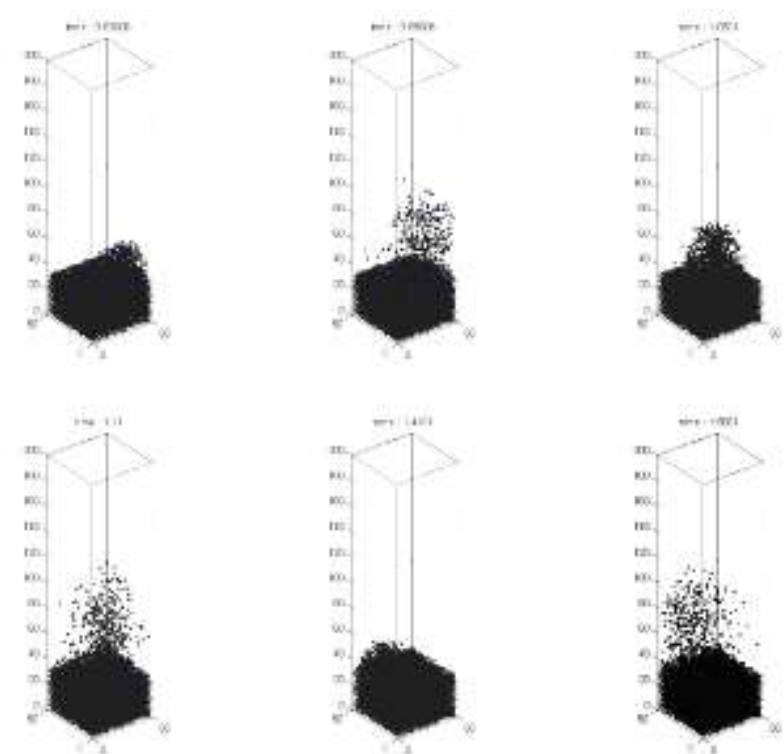

Figure 9. The motion of particle in multi-pulsed spouted bed at frequency $=2.5 \mathrm{~Hz}$
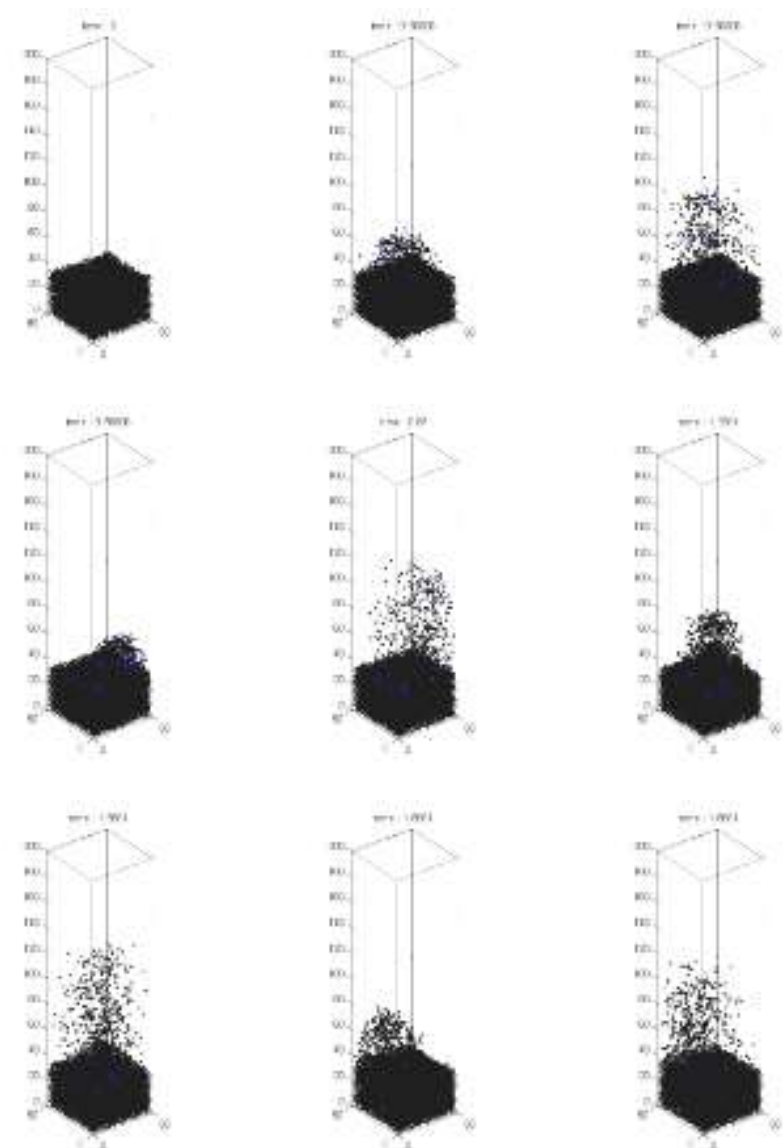

Figure 10. The motion of particle in multi-pulsed spouted bed at frequency $=2.0 \mathrm{~Hz}$

From the above figures, the motion of particles in the multi-pulsed spouted bed differs from the pulsed spouted bed. The multi-pulsed spouted bed can distribute the heat from hot air to the particles in every area in the chamber more than the continuous and pulsed flow. For the average particle temperature, it increases when the time increases. This is similar to the case of single pulsed flow spouting but it different in the temperature of particles in the bed. 


\subsection{Comparison of the Hot Air Flow type in the Spouted Bed}

This section will compare the average particle temperature from the many types of hot air flow that are the continuous flow, the pulsed flow, and the multiple pulsed flows. The frequency used in this section for the pulsed flow and multiple pulsed flow spouting is 0.33 Hertz. From the simulation, the continuous flow gives the highest average particle temperature. The trend of pulsed flow was similar multiple pulsed flows but the average particles temperature has a small different. The average particles temperature of the multiple pulsed flows is higher than the pulsed flow. Moreover the multiple flows have a good distribution of the heat transfer of the particles and it can reduce the dead zone problem.

\section{CONCLUSION}

Spouted bed is the one of the technique allowing the direct contact between the fluid and solid particle. In this study, mathematical model of the spouted bed was developed in order to be a tool for study its phenomena. The calculation of the hydrodynamic inside the spouted bed can be divided into 2 major parts; particle motion and fluid motion, The DEM was applied to calculate the interaction forces between particle-particle and particle-wall contact. The fluid motion was calculated using CFD which based on local averaged quantities. The numerical simulation can give more data for each particle than that obtained from an experiment such as particle velocity, interaction forces between particle and particle position.

The program was developed firstly and tested with some artificial cases to see the realistic of the particle motion. Then the initial positions of the particle were determined by random the particles and then let them fall by gravitational force to pack in the bed. There are two shapes of the spouted bed studied in this work. The first one is the rectangular shape and the other one is the cylindrical shape. However, in this research, the program for simulate the combining of the particle motion and fluid motion for the cylindrical cannot be completed. Therefore, the results will focus only on the rectangular spouted bed.

The results show that the operating parameters which are the pressure drop across the bed and the minimum spouting velocity go up with the increasing of the static bed height. For the effect of the pulsed and multi-pulsed frequency, higher number of frequency will give the higher heat transfer to the particles. Moreover, when compare the average particles temperature for each type of hot air flow which are continuous flow, pulsed flow, and multiple pulsed flows, the continuous flow gives the highest average particles temperature. The multiple pulsed flow gives the higher average particles temperature than the single pulsed flow and it has a very good distribution of the heat transfer and also can reduce the dead zone problem in the spouted bed.

\section{NOTATION}

$\mathrm{d}=$ Distance Between the Centre of Two Particles in Contact

$\mathrm{E}_{\mathrm{p}} \quad=$ Young's modulus for the particle material

$\mathrm{E}_{\mathrm{W}}=$ Young's modulus for the wall material

$\mathrm{f}_{\mathrm{c}} \quad=$ Contact Force

$\mathrm{f}_{\mathrm{cn}}=$ Contact Force in Normal Direction

$\mathrm{f}_{\mathrm{cs}}=$ Contact Force in Shear Direction

$\mathrm{f}_{\mathrm{dn}} \quad=$ Damping Force in Normal Direction

$\mathrm{f}_{\mathrm{ds}} \quad=$ Damping Force in Shear Direction

$\mathrm{f}_{\mathrm{f}} \quad=$ Fluid Drag Force

$\mathrm{g}=$ Gravitational Acceleration

$\mathrm{i}, \mathrm{j}, \mathrm{k}=$ Direction Index, 1, 2, 3 refer to $\mathrm{X}, \mathrm{Y}$ and Z-Direction, respectively

I $=$ Moment of Inertia

$\mathrm{k}_{\mathrm{n}} \quad=$ Normal Spring Constant

$\mathrm{k}_{\mathrm{s}} \quad=$ Shear Spring Constant

$\mathrm{m}=$ Mass of Particle

$\mathrm{n} \quad=$ Unit Normal Vector 


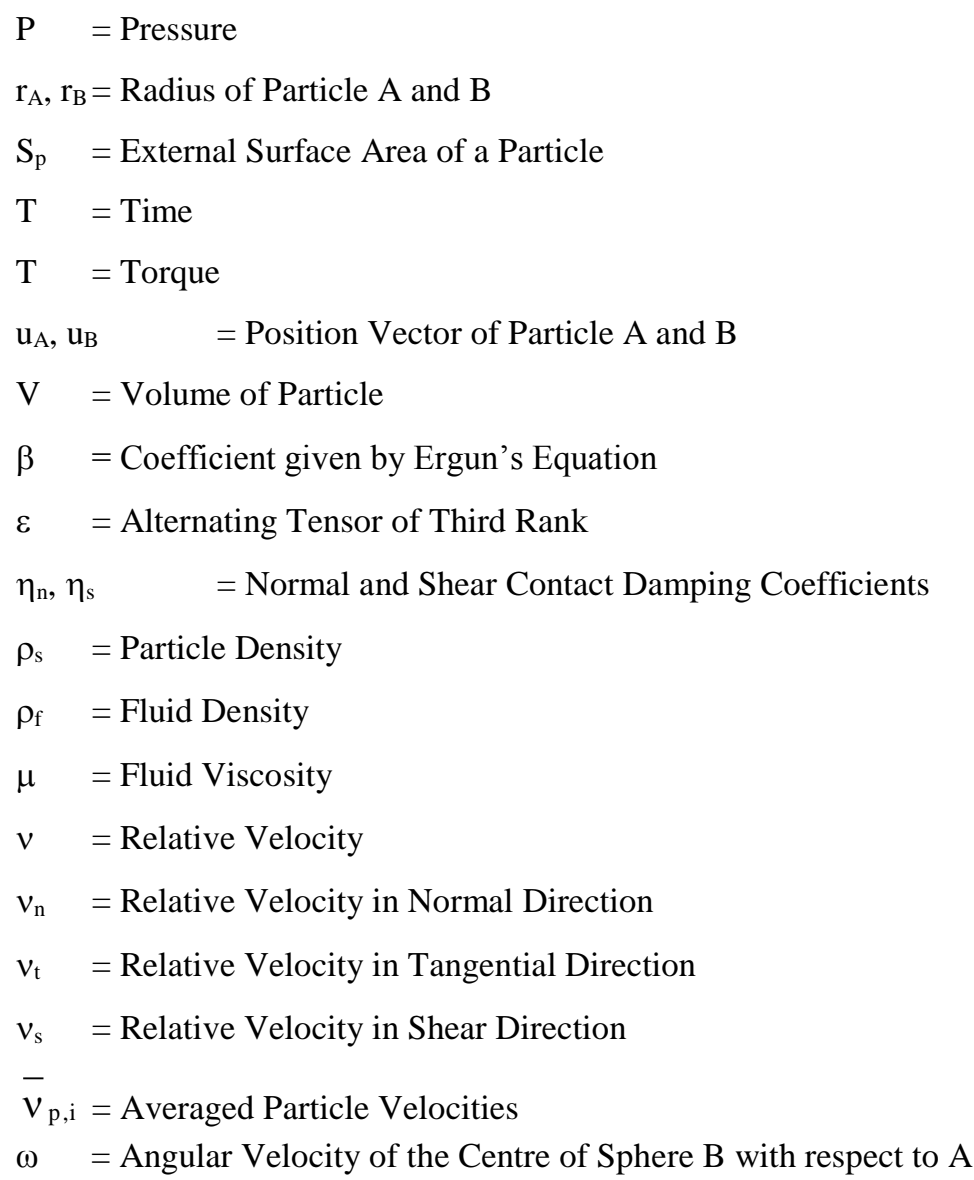

\section{REFERENCES}

[1] Cundall, P.A. and O.D.L Strack.,1979, A Discrete Numerical Model for Grannular Assemblies, Geotechnique 29(1):47-65

[2] Mathur, K.B. and Epstein,N.,1974, Spouted Beds, Academic Press, New York, pp. 1-122.

[3] Ergun, S., 1952, Chemical Engineering Progress, Vol. 48, No.2, pp.123-232

[4] Wen, C.Y. and Yu, Y.H., 1996, Chemical Engineering Progress, Series 62, Vol. 62, pp.143-156.

[5] Suntharasmai, S., 2002, Simulation of Momentum and Heat Tranfer in a Vibrated Fluidized Bed, Master of Engineering Thesis, Chemical Engineering Program, Faculty of Engineering, King Mongkut's University of Technology Thonburi, pp. 1-70 